\section{Modelling and predicting mammalian wildlife abundance and distribution in semi-arid Gonarezhou National Park, south eastern Zimbabwe}

\author{
Talent Murwendo
}

Department of Physics, Geography and Environmental Science, Faculty of Agriculture and Natural Sciences, Great Zimbabwe University, Masvingo, Zimbabwe

Amon Murwira

Department of Geography and Environmental Science, Faculty of Science, University of Zimbabwe, Harare, Zimbabwe, and

Mhosisi Masocha

Department of Geography and Environmental Science, University of Zimbabwe, Harare, Zimbabwe

\begin{abstract}
Purpose - The purpose of this study is to model and predict mammalian herbivore species abundance in Gonarezhou National Park (GNP), south eastern Zimbabwe. The study also aims to determine and evaluate the distribution-abundance patterns in GNP.
\end{abstract}

(C) Talent Murwendo, Amon Murwira and Mhosisi Masocha. Published in Ecofeminism and Climate Change. Published by Emerald Publishing Limited. This article is published under the Creative Commons Attribution (CC BY 4.0) licence. Anyone may reproduce, distribute, translate and create derivative works of this article (for both commercial and non-commercial purposes), subject to full attribution to the original publication and authors. The full terms of this licence may be seen at http:// creativecommons.org/licences/by/4.0/legalcode

Author would like to extend our gratitude to Great Zimbabwe University for support and allowing the use of their facilities and equipment. Many thanks are extended to Zimbabwe Parks and Wildlife Authority and Frankfurt Zoological Society particularly Elsabe Van der Westhuizen for availing data on mammalian herbivore species.

Author contributions: Talent Murwendo: Conceptualisation of study and writing the original draft manuscript.

A. Murwira: conceptualisation of the study.

M. Masocha: Study design and write up.

Disclosure statement

There is no conflict of interest to report on.

Data availability statement

Data used in this study was obtained from the Frankfurt Zoological Society in Chipinda Pools, Chiredzi

Contact person: Elsabe.vdwesthuizen@fzs.org

Data deposition

website: www.uz.ac.zw/science/geography/
Mammalian wildlife abundance 
EFCC 1,3

Design/methodology/approach - Using aerial survey data from 1980 to 2016, the authors use the rankabundance model to determine the abundance of mammalian herbivores in GNP. Regression analysis is used to show the mammalian herbivore species distribution-abundance relationship.

Findings - The findings point to a high species richness and evenness in the study area with common species $(15 \%)$, intermediate $(30 \%)$ and rare $(60 \%)$. There is a positive significant relationship $\left(p=0.00, R^{2}=\right.$ 0.9642 ) between abundance and distribution with common species occupying wider spaces and rare species occupying narrow spaces.

Research limitations/implications - Aerial surveys in GNP are not continuous and are biased towards elephants. The inclusion of other mammalian herbivore species including domestic animals in subsequent surveys made the aerial reports useful.

Originality/value - Studies in GNP have tended to concentrate on the population of mammalian herbivores and this marks a shift in emphasis in such studies. The monitoring of mammalian species improves the conservation and management of GNP. Apart from making planning and policy decisions from an informed point of view small animals also need attention as they are numerically few than the large threatened mammals.

Keywords Wildlife, Wildlife abundance, Wildlife distribution, Mammalian herbivore species, Gonarezhou National Park, Semi-arid savanna, Abundance-distribution relationship

Paper type Research paper

\section{Introduction}

Wild animals, particularly mammalian herbivore species are important for ecosystem health and status (Khaemba, 2000; Villarreal et al., 2013). They help to maintain the balance of an ecosystem as they form a link in energy flows within the ecosystem (Taylor et al., 2018). Mammalian herbivore species depend on vegetation and carnivorous species depend on them for survival. Some keystone mammalian herbivore species also regulate the growth of vegetation, soil structure and water availability (Verberk, 2011). Due to their co-occurrence, interaction and competition they affect vegetation distribution, phenology and morphology (Taylor et al., 2018; Pettorelli et al., 2009). Similarly, the abundance and distribution of herbivore species mammals vary within a landscape. Large common mammalian herbivore species have an influence on small rare mammals as they compete for resources and sometimes with detrimental negative effects when small mammals are exposed to predators (Taylor et al., 2018). It is, therefore, critical to know the abundance and distributional patterns of mammalian herbivore species in south east Zimbabwe. In this study, we model and predict mammalian herbivore species to determine their relative abundance and distribution in semi-arid savanna Gonarezhou National Park (GNP), an important vehicle for economic development in south eastern Zimbabwe. Understanding mammalian herbivore species relative abundance and their distribution are important in the conservation and management of mammalian species and their habitat. In GNP little is known about the relative abundance of mammalian herbivore species and their perceived spatial distribution. While the population of each mammalian herbivore species is known, competition and interaction of such species at habitat level needs to be improved. The identification of abundant common species and rare more often, smaller and few species will, in turn, determine species richness and evenness of an ecosystem (Verberk, 2011; Gandiwa et al., 2013; Winterbach et al., 2015).

Globally, mammalian herbivore species are under threat due to human encroachment and environmental changes (Dunham, 2012; Khaemba, 2000; Villarreal et al., 2013). In GNP, poaching of wild animals and other resources, as well as encroachment by settlements have become common ((Dunham, 2012; Gandiwa et al., 2013). Trends on the rapidly changing nature of ecological landscapes at a global level have necessitated the need for monitoring of 
large and small mammalian herbivore species using available aerial survey data (ChamailléJammes et al., 2007; Pettorelli et al., 2009; Redfern et al., 2002; Schlossberg et al., 2016; Walter and Hone, 2003). There has been an increase in data on mammalian herbivore species through aerial surveys in semi-arid parts of southern Africa and East Africa (Oindo, 2008; Omondi et al., 2006; Pettorelli et al., 2009; Walter and Hone, 2003). However, the literature on mammalian species relative abundance and distribution in GNP has not correspondingly increased despite availability of such aerial survey data.

The significance of understanding mammalian herbivore species relative abundance and

Mammalian wildlife abundance distribution within ecosystems has been recognised for quite some time and pioneered through research (Verberk, 2011; Preston, 1948; Winterbach et al., 2015; Magurran, 2004; Matthews and Whittaker, 2014; Preston, 1948). Models were formulated that highlight species abundance (Magurran, 2004) and critiqued (Matthews and Whittaker, 2014). General conclusions indicate that few species are at the high abundance and many at intermediate and low abundances, (Barker et al., 2014; Godfray and Lawton, 2001; Matthews and Whittaker, 2014; Preston, 1948). Similarly, a positive relationship exists between distribution and abundance of species (Verberk, 2011), with common species being widespread and rare species being thinly spread over an area (Johnston et al., 2015; Magurran, 2004; Verberk, 2011).

Lognormal curve (Preston, 1948), broken stick curve, log series, neutral theory and the geometric series models are some of the models used to depict abundance (Matthews and Whittaker, 2014). While these models have been tried and tested on plants and animals at different scales the lognormal curve theory has stood the test of time (Magurran, 2004; Matthews and Whittaker, 2014; Oliveira and Batalha, 2005). The rank-abundance plot is advantageous in that it displays contrasting patterns of abundance (Magurran, 2004). Technical challenges have been highlighted (Villarreal et al., 2013; Magurran, 2004) where species are numerous. Modelling patterns of species relative abundance has become increasingly regular and popular in many parts of the world (Johnston et al., 2015; Magurran, 2004; Johnston et al., 2015; Oindo and Skidmore, 2002; Walter and Hone, 2003).

Data on species abundance have become easier to obtain through aerial surveys of mammalian herbivore species distribution, which are increasing in southern Africa (Dunham, 2012; Johnston et al., 2015; Schlossberg et al., 2016; Walter and Hone, 2003; Winterbach et al., 2015). In GNP, studies using aerial survey data concentrated on elephants and other large mammalian herbivore species' population's increase (Dunham, 2012). However, reliance on aerial surveys alone for such studies has been questioned (Ndaimani et al., 2017; Redfern et al., 2002). Despite the questions around the use of aerial surveys census counts, they remain an emerging data source and a stepping stone towards an assessment of wildlife governance.

Using GNP census reports between 2000 and 2016, the major objective of this study is to determine mammalian herbivores species relative abundance and distribution using aerial survey data in GNP, south eastern Zimbabwe since 2000 AD. Specifically, we first model large mammalian herbivore species relative abundance using the rank-abundance model (Whitaker model) and secondly, test the distribution-abundance relationships in semi-arid savanna GNP.

\section{Materials and methods \\ Study area (Figure 1)}

GNP is part of the Greater Limpopo Transfrontier Conservation Area, designated to protect and conserve the ecological landscape particularly biodiversity in south eastern Zimbabwe. It is the second-largest protected area in Zimbabwe covering about $5,053 \mathrm{~km}^{2}$ (Dunham, 


\section{EFCC}

1,3

154

Figure 1.

Gonarezhou National Park in south eastern Zimbabwe $\left(-21^{\circ}\right.$ $0.399^{\circ} 59.99^{`} \mathrm{~S} ; 31^{\circ}$ $\left.0.399^{`} 59.99^{`} \mathrm{E}\right)$

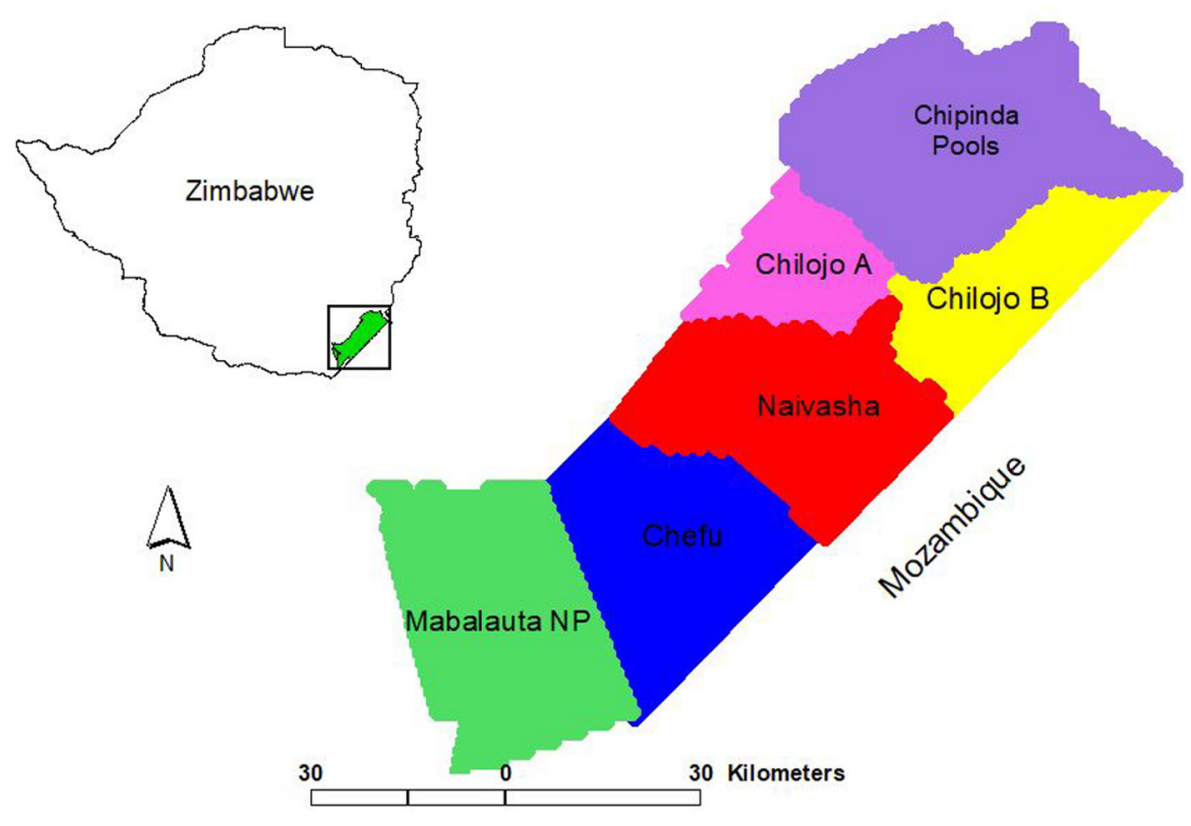

Notes: Six census strata were used and their percentage area in brackets; Chipinda Pools (23.58), Chilojo A (9.29), Chilojo B (12.16), Naivasha (17.86), Chefu (20.55) and Mabalauta (16.57), which were consistently used for Mammalian herbivore counts from 2001-2016

2012; Gandiwa, 2013; Gandiwa et al., 2013). GNP is a hot and dry low-lying area, therefore crop cultivation is difficult and wildlife management becomes a favourable economic activity (Dunham and Mackie, 2002).

Vegetation, which forms part of the habitat for mammalian herbivore species, comprise of southern African Bushveld, southern miombo woodlands, Zambian and Mopane woodlands biomes and is an important source of food and shelter for herbivores (Cunliffe et al., 2017; Gandiwa, 2013). Deciduous forested broadleaved woodlands with a mixture of shrublands and grassland are common. Colophospermum Mopane, dominated by dry deciduous savanna woodlands comprising physiognomic types of $59 \%$ woodland savanna, 40\% scrubland and 1\% savanna grassland (Cunliffe et al., 2017; Gandiwa, 2011; Gandiwa et al., 2013; Martin et al., 2016) make up the classifications. Shrublands thrive on deep sandy alluvium soils and are surrounded by acacia trees, while forested deciduous woodlands of Julbernadia globiflora, Brachystegia glaucescens and Guiborrtia conjugata are found in sandstone and basaltic Central GNP. A mixture of Mopane woodlands, scrubland and grasslands are found in southern GNP (Dunham and Gandiwa, 2009; Dunham, 2013; Martin et al., 2016; Clegg and O'Connor, 2012).

A number of herbivore mammalian species, namely, elephants (Loxodonta Africana), buffalo (Syncerus caffer), zebra (Equus quagga burchelii), giraffe (Giraffa Camelopardalis), kudu (Tragelampus strepsiceros), impala (Aepyceros melampus), eland (Taurotragus oryx), nyala, (Tragelampus augastic), wildebeest (Connochaetes taurinus), waterbuck (Kobus ellipsiprymnus), warthog (Phacochoerus africanus), common duiker (Sylvicapra grimmia), 
steenbok (Raphicerus campestris), ostrich (Struthio camelus), grysbok (Raphicerus melanotis), sable (Martes zibellina) and of late cattle (Bos Taurus), sheep (Ovis aries), goats (Capra aegagrus hircus) both treated as shoats in this research and donkeys (Equus africanus asinus) have been observed (Dunham, 2012).

\section{Aerial census data}

Aerial survey census counts for GNP have been carried out since 1980 to date (Dunham, 2012; Dunham and Mackie, 2002; Ndaimani et al., 2017). The census surveys in GNP were and are still biased towards elephants as defined by the search effort and sampling intensity (Dunham et al., 2007; Dunham, 2013). Aerial surveys in GNP were conducted in 1980, 1981, 1982, 1983, 1984, 1986, 1987 and 1989 (Dunham, 2013). In the 1990s, some large mammalian herbivore species were added to the census counts particularly in 1991, 1995, 1996 and 1999. Since 2000s, comprehensive aerial surveys were conducted in 2001, 2007, 2009, 2013, 2014 and 2016 (Dunham and Van der Westhuzein, 2016).

Aerial census count surveys in GNP used GPS receiver fitted small aircraft flying at an average of $170 \mathrm{~km} / \mathrm{h}$ and a height of $296 \mathrm{~m}$ above the ground (Dunham, 2012). CITES MIKE programme standards were used (Dunham, 2013) so that the data are comparable with earlier surveys especially for the 2001 survey. Systematic parallel transects with a width of $300 \mathrm{~m}$ were demarcated in each stratum (Dunham and Gandiwa, 2009; Dunham, 2013). The sampling intensity of $12 \%$ was used. Other mammalian herbivore species including domestic livestock such as Equus africanus asinus, Bos Taurus, Ovis aries and Capra aegagrus hircus (collectively referred to as shoats) were also included as they contributed to the degradation of the national park.

The 2001, 2007, 2009, 2013, 2014 and 2016 surveys were the only ones conducted for GNP between 2000 and 2016. These were, however, comprehensive, comparable and included a variety of mammalian herbivore species (Dunham, 2013; Dunham et al., 2007; Dunham, 2012; Dunham and Gandiwa, 2009). The results of the census counts were obtained from Frankfurt Zoological Society stationed at Chipinda Pools, Chiredzi. A year in which some of the species were not included it was assumed that such animals were not observed. Sampling intensity was no less than $20 \%$ in all the census counts.

The hippopotamus (Hippopotamus amphibious), the crocodile (Crocodylus porosus), Loxodonta Africana carcasses, the ground hornbill (Bucorvus leadbeateri) and poachers' tents were left out for a number of reasons related to data compatibility. Each of the selected mammalian herbivore species was recorded and their totals tallied with the total for the whole of GNP. Ultimately, each strata for GNP became an important entry point for data analysis rather than the census count years.

\section{Data analysis}

The frequency of occurrence in the strata was used to classify mammalian herbivores species, with percentages greater than $60 \%$ classified as common, 30-60\% as intermediate and less than $30 \%$ as rare. The mammalian herbivore species were ranked in decreasing order of abundance, the most abundant specie was ranked as 1 and the second most as 2 up until the least abundant species. These were placed on the $x$-axis as rank. The relative abundance of species was placed on the $y$-axis as a percentage. Even though the number of mammalian herbivore species was small, the data was log-transformed to reduce the clustering of data at lower levels in the testing of the distribution-abundance relationship curve. Measures of an abundance-distribution relationship were calculated as the mean density of each species across all the strata where each species occupied over a six-year period. The computation of local density for each species was performed by taking density
Mammalian wildlife abundance 
EFCC

1,3

\section{6}

in each occupied stratum and then averaging them across the years. Similarly, the measures of distribution were simplified to confinement to the number of strata occupied and the presence of mammalian herbivore species. Distribution-abundance relationship was obtained by plotting abundance on the $y$-axis and distribution on the $x$-axis. A goodness of fit line through regression analysis was used to test the significance of the relationship.

\section{Results}

Patterns in species abundance in Gonarezhou National Park

The results on abundance show two important trends in GNP. Firstly, the spatial distribution of mammalian herbivore species indicates the total number of species, the percentage of species and species richness in GNP in each stratum (Table 1). Mammalian herbivore species' commonness and rarity classes are indicated as $15 \%$ of the species are common, $25 \%$ are intermediate while about $60 \%$ are rare (Table 2). Some species were observed irregularly in census strata as Chilojo A and B, the roan antelope (Hippotragus equinus) was observed only once in 2007 while the Raphicerus melanotis was observed once in 2009, at the same time domesticated animals (Bos Taurus, Ovis aries, Capra aegagrus hircus and Equus africanus asinus) are regular sights on strata sharing the boundaries with settlements and are becoming moderately common in the Mabalauta stratum. Bos Taurus has increased in abundance and distribution since $2000 \mathrm{AD}$ except for strata further away from settlements such as Chilojo B, Naivasha and Chefu. Ovis aries and Capra aegagrus hircus are also prevalent but on the rare side while Equus africanus asinus are also rarer. The Taurotragus oryx and the Aepyceros melampus are featuring quite often on common species. In Chipinda pools, the Aepyceros melampus is the dominant species than the Loxodonta Africana.

Secondly, the result shows the rank-abundance distribution for mammalian herbivore species in each stratum and GNP. In all cases, there is a dominance of two or three species with clustering at the lower ranks. The hierarchical distribution is shown in Figure 2 below.

\section{Distribution-Abundance relationships}

Regression analysis showed a significant positive relationship $\left(\phi=0.000 ; R^{2}=0.9641\right)$ between the distribution and abundance. An increase in an area results in a corresponding increase in density. Figure 3 shows that the abundant herbivore species with high densities occupying larger areas in GNP and rare species with low densities are clustered in smaller specific areas. Common mammalian herbivore species occur at more sampling localities and rare mammalian herbivore species are narrowly distributed. The common species are found in all the census strata at dominant levels and have a high density at around between $0.85 / \mathrm{km}^{2}$ to $4.0 / \mathrm{km}^{2}$. Rare herbivore species have lower densities and are clustered on smaller proportions of land (Table 3 ).

Table 1.

A summary of the total estimate, percent of estimated species and species richness of census strata and GNP

\begin{tabular}{lccc}
\hline Stratum & Total no. of species & Percent of total species & Individual species present \\
\hline Chipinda & 10,340 & 38.62 & 16 \\
Chilojo A & 2,657 & 9.92 & 16 \\
Chilojo B & 5,361 & 20.02 & 17 \\
Naivasha & 1,928 & 7.20 & 15 \\
Chefu & 2,825 & 10.55 & 14 \\
Mabalauta NP & 3,666 & 13.69 & 19 \\
Total & 26,777 & 100 & 19
\end{tabular}




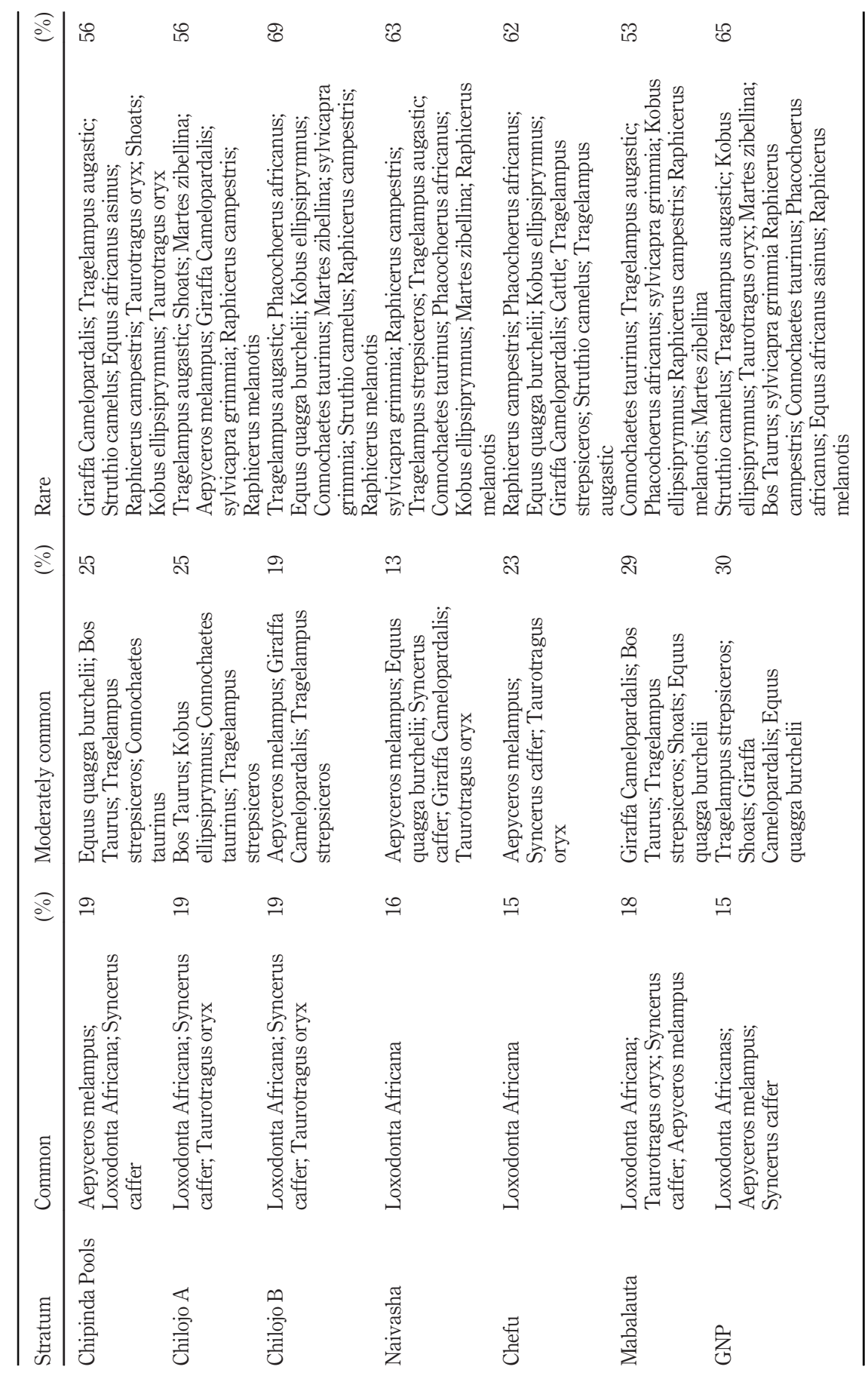

Mammalian wildlife abundance

Table 2.

The common, intermediate and rare species in the six strata and GNP in general between 2000 and 2016 


\section{EFCC}

1,3

\section{8}

Figure 2.

Rank abundance distribution for Chipinda Pools, Chilojo A, Chilojo B, Naivasha, Chefu Mabalauta and GNP

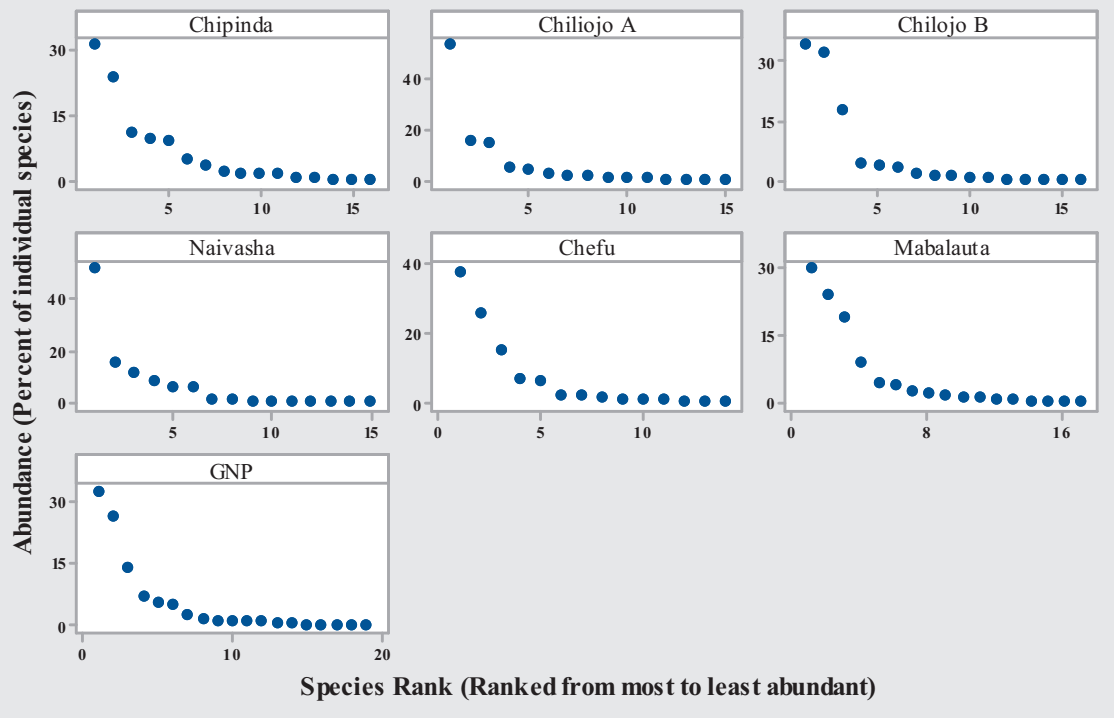

Notes: The overall rank abundance distribution for GNP is calculated from a total abundance of individual species for each stratum. The high species evenness is shown by the clustering of species at lower levels. Except for Mabalauta and GNP, the other strata show a species richness not extending 16 species as compared to the 19 species under consideration

\section{Discussion}

Patterns of species abundance

The results of the study show patterns of mammalian herbivore species abundance and their distributional patterns in GNP. The results indicate the common, intermediate and rare herbivore species and their proportions in GNP. We note the dominance of at least three common species in each strata and a sizeable number of the intermediate and rare species. The hierarchical distribution shows the dominating species in GNP is made up Loxodonta Africana; Aepyceros melampus; Syncerus caffer. However, Aepyceros melampus has been increasing in population and will be challenging the top position occupied by Loxodonta Africana (Dunham et al., 2007). The rare species are numerous and are clustered at lower levels as shown in Table 2. The rare species co-exist with the dominating species in each stratum and hence compete for resources with dominating species. This makes rare species vulnerable as they have to compete with the dominating species for resources and this may expose them to predation and extinction (Verberk, 2011).

The clustering of mammalian herbivore species at lower levels indicates species evenness for the GNP strata in general. As shown by Figure 2, the species richness for Mabalauta, Chilijo A and Chilojo B are high, perhaps, because of favourable habitat conditions of these areas (Gandiwa et al., 2013) while Chipinda Pools, Naivasha and Chefu are low due to the rugged nature of the terrain (Dunham, 2012) as rare species are pushed into low-lying areas a situation that would result in such habitats being degraded (Taylor et al., 2018). Rare species would require monitoring, management and conservation 


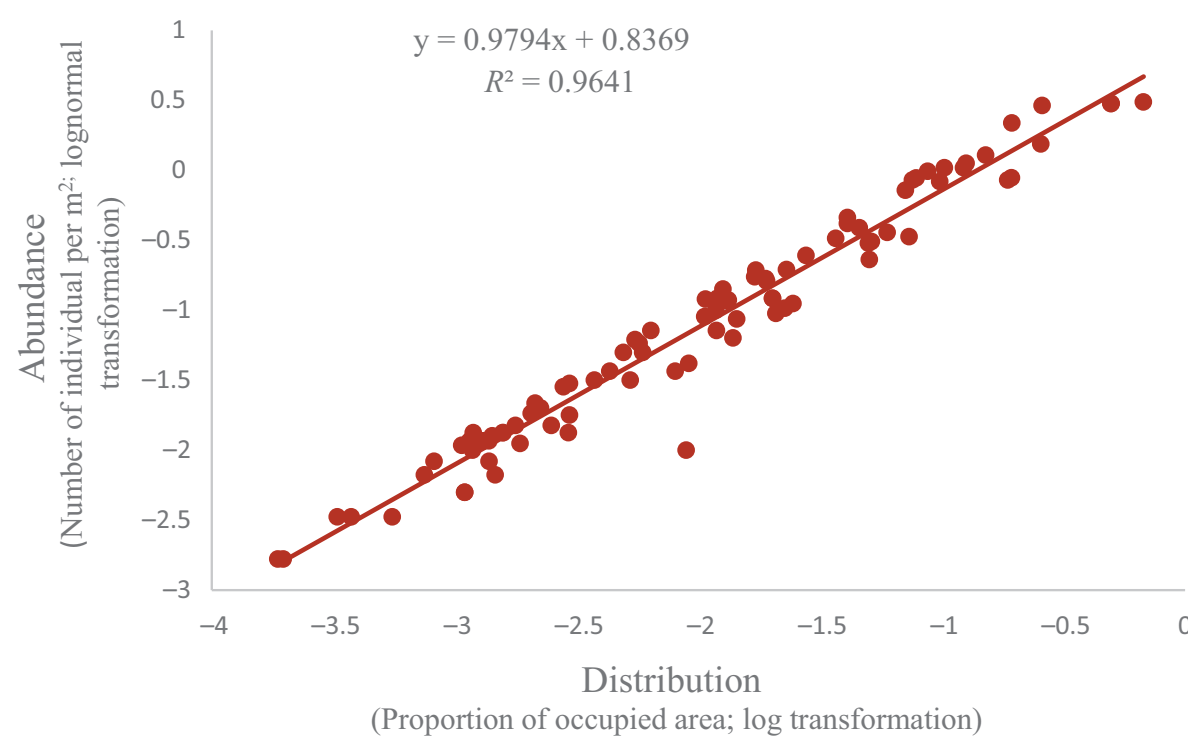

Note: A significant $(p=0.00)$ positive linear relationship between abundance $($ density $)=0.8369+0.9794 *$ distribution (proportion of occupied area)

\begin{tabular}{lcccccc}
\hline Variable & Coefficient & SE coefficient & $t$-value & $p$-value & $R^{2}$ & Adjusted $R^{2}$ \\
\hline Constant & 0.84 & 0.04 & 19.10 & 0.00 & 0.96 & 0.96 \\
Area & 0.98 & 0.02 & 48.37 & 0.00 & &
\end{tabular}

Notes: Abundance-density $=0.84+0.98 \%$ of the occupied area. An increase in area by a single unit will result in an increase of 0.98 in density.
Mammalian wildlife abundance

Figure 3.

Distributionabundance relationship of GNP

Table 3. Regression parameters for distributionabundance relationships in GNP

measures aligned towards their proliferation (Taylor et al., 2018). Verberk (2012) contends that clustering is related to what he termed specialists species, which would occupy homogenous areas as opposed to what he termed generalists herbivores, particularly the common species, which are selective in their foraging habits would occupy heterogeneous areas.

Studies on species abundance, as well as richness and evenness patterns carried out by a number of authors whose results are similar to trends found in GNP (Barker et al., 2014; Fauchald et al., 2017; Johnston et al., 2015; Pettorelli et al., 2005; Villarreal et al., 2013b; Winterbach et al., 2015). The studies covered various aspects such as plants and insects. In these studies, practical use of such studies especially in tourism has been singled out (Winterbach et al., 2015) an activity that can benefit GNP.

Another important observation from the study is that in GNP there are mammalian herbivore species, which have been sited in some strata that never existed before like the Tragelampus augastic whose population has been increasing in recent years (Gandiwa, 2011; Gandiwa et al., 2013; Dunham et al., 2007). An increasing number of domesticated 
EFCC 1,3

animals in GNP aerial surveys that cannot be ignored anymore. This is because of increased settlements around GNP and this has caused human-wildlife conflicts especially given the increasing number of mammalian herbivores in GNP (Gandiwa et al., 2013; Dunham, 2013; Dunham et al., 2007; Dunham, 2012). Given the above issues, it has to be reiterated that monitoring and conservation measures such as restoration (Verberk, 2011), translocation and introduction of new species will be carried out with a clear understanding of abundance and distribution patterns.

\section{Distribution-abundance relationships}

Regression analysis shows a positive linear relationship between mammalian herbivore distribution and their abundance in GNP. Quantifying distribution-abundance relationships is becoming common in community ecology (Verberk, 2011; Khaemba, 2000; Villarreal et al., 2013) and this points towards habitat modification. In GNP observations are that common herbivore species have a widespread distribution and the rare species have a narrow distribution as is often the agreed observations (Kerr and Ostrovsky, 2003; Pettorelli et al., 2009; Walter and Hone, 2003). This has often resulted in the grouping of herbivore species into those that can survive on a wide heterogeneous geographical distribution and those that survive on specific local homogenous environmental conditions particularly patches (Barker et al., 2014; Khaemba and Stein, 2000; Matthews and Whittaker, 2014). However, these results may be influenced by a low number of species considered or the dry period when the aerial surveys were carried out when species tend to congregate along with scarce resources.

Mammalian herbivore species such as the Loxodonta Africana, Aepyceros melampus and Syncerus caffer in GNP maintain their numbers by positive feedback mechanisms as they produce more offsprings because of their numbers, which allow the species to increase and may maintain this position for some time. This results in more colonisation and expansion of their habitat (Verberk, 2011). Stochastic factors such as birth, death, immigration, extinction and speciation (Dunham, 2012; Godfray and Lawton, 2001; Khaemba and Stein, 2000; Schlossberg et al., 2016) are other factors, which result in an increase in population. The introduced Taurotragus oryx in GNP (Dunham, 2013) whose numbers are becoming noticeable is because of the above. However, biophysical conditions such as droughts will restrict the survival and reproduction of species where diet, reproduction, dispersal and habitat specialisation are considered. Competition and predation have a role to play in increasing populations of rare species, which are localised (Verberk, 2011; Gandiwa et al., 2013; Oindo and Skidmore, 2002; Pettorelli et al., 2009) mostly in a reduction of their numbers. Neutral and niche dynamics are important elements in considering the restoration of communities in protected areas like GNP. However, migration patterns have not been considered extensively at different times of the year to make comparisons effective.

The increasing number of domesticated animals in strata such as Chipinda pools, Chilojo A and Mabalauta is explained by the fact that the period under study is associated with a revolutionary land reform approach in Zimbabwe and peripheral grazing of parts of GNP particularly those close communal lands are affected by encroachment. The abundance of cattle has been noted in Chipinda Pools and Mabalauta NP and has led to competition for GNP resources (Beck and Suring, 2015; Gandiwa, 2013; Gandiwa et al., 2013). Incidences of poaching of resources particularly wildlife had also increased but now look curtailed were also related to encroachment.

The rank-abundance distribution and distribution-abundance relationships are important ways of highlighting herbivore species patterns in a protected area. The models are important in highlighting the conservation and management needs of GNP. Herbivore species, which are endangered and threatened can be identified and possible remedies 
quickly implemented. An increasing trend for herbivore species population requires an understanding of their habitat and their carrying capacities.

\section{Conclusion}

The rank-abundance model and regression could be used to depict the abundance and distribution of mammalian herbivore species successfully in GNP. Mammalian herbivore species spatial abundance is more in Mabalauta, Chipinda and Chiliojo B. Similarly a hierarchical distribution of mammalians is observed with a dominance of four wildlife species. The dominant species are common and the rest of the species are clustered in the intermediate and rare species. Distribution-abundance relationships show that common species occupy heterogenous habitats while rare species are found in homogenous habitats. Aerial census surveys can be depended upon to show mammalian herbivore species, particularly if they are systematic and comprehensive. Studies of a similar nature need to be extended to carnivorous wildlife and insects, as well as vegetation. There is a need to distinguish vegetation species in terms of occurrence in GNP to improve wildlife protection measures.

\section{References}

Barker, N.K.S., Slattery, S.M., Darveau, M. and Cumming, S.G. (2014), "Modeling distribution and abundance of multiple species: different pooling strategies produce similar results", Ecosphere, Vol. 5 No. 12, pp. 1-24.

Chamaillé-Jammes, S., Valeix, M. and Fritz, H. (2007), "Managing heterogeneity in elephant distribution: interactions between elephant population density and surface-water availability", Journal of Applied Ecology, Vol. 44 No. 3, pp. 625-633.

Clegg, B.W. and O'Connor, T.G. (2012), "The vegetation of Malilangwe wildlife reserve, South-Eastern Zimbabwe", African Journal of Range and Forage Science, Vol. 29 No. 3, pp. 109-131.

Dunham, K.M. (2012), "Trends in populations of elephant and other large herbivores in Gonarezhou national park, Zimbabwe, as revealed by sample aerial surveys", African Journal of Ecology, Vol. 50 No. 4, pp. 476-488.

Dunham, K.M. (2013), Aerial survey of elephants and other large herbivores in Gonarezhou National Park (Zimbabwe) and surrounding areas: 2013 Report, Frankfurt Zoological Society and Zimbabwe Parks and Wildlife Management Authority Harare.

Dunham, K.M. and Gandiwa, E. (2009), Aerial survey of elephants and other large herbivores in Gonarezhou National Park (Zimbabwe), Zinave National Park (Mozambique) and surrounds: 2009 Report, Frankfurt Zoological Society and Zimbabwe Parks and Wildlife Management Authority, Harare.

Dunham, K.M. and Mackie, C.S. (2002), National summary of aerial census results for an elephant in Zimbabwe: 2001 Report, Department of National Parks and Wildlife Management and WWFSARPO, Harare.

Dunham, K.M. and Van der Westhuzein, H. (2016), Aerial survey of elephants and other large herbivores in Gonarezhou National Park (Zimbabwe) and some adjacent areas: 2016 Report, Frankfurt Zoological Society and Zimbabwe Parks and Wildlife Management Authority, Harare.

Dunham, K.M., Mackie, C.S., Zhuwau, C., Taylor, R.D. and Chimuti, T. (2007), Aerial survey of elephants and other large herbivores in Gonarezhou National Park, Zimbabwe: 2007 Report, Frankfurt Zoological Society and Zimbabwe Parks and Wildlife Management Authority, Harare.

Fauchald, P., Park, T., Tømmervik, H., Myneni, R. and Hausner, V.H. (2017), "Arctic greening from warming promotes declines in caribou populations", Science Advances, Vol. 3 No. 4, pp. 1-9.
Mammalian wildlife abundance 


\section{EFCC}

1,3

Gandiwa, E. (2011), "Preliminary assessment of illegal hunting by communities adjacent to the Northern Gonarezhou national park, Zimbabwe”, Tropical Conservation Science, Vol. 4 No. 4, pp. $445-467$.

Gandiwa, E. (2013), "Vegetation factors influencing density and distribution of wild large herbivores in a Southern African savannah”, African Journal of Ecology, Vol. 52 No. 3, pp. 274-283.

Gandiwa, E., Heitkonig, I.M.A., Gandiwa, P., Matsvayi, W., Van der Westhuizen, H. and Ngwenya, M. M. (2013), "Large herbivore dynamics in Northern Gonarezhou national park, Zimbabwe", Tropical Ecology, Vol. 54 No. 3, pp. 345-354.

Godfray, H.C.J. and Lawton, J.H. (2001), "Scale and species numbers", Trends in Ecology and Evolution, Vol. 16 No. 7, pp. 400-404.

Johnston, A., Thaxter, C.B., Austin, G.E., Cook, A.S.C.P., Humphreys, E.M., Still, D.A., Mackay, A., Irvine, R., Webb, A. and Burton, N.H.K. (2015), "Modelling the abundance and distribution of marine birds accounting for uncertain species identification", Journal of Applied Ecology, Vol. 52 No. 1, pp. 150-160.

Kerr, J.T. and Ostrovsky, M. (2003), "From space to species: ecological applications for remote sensing", Trends in Ecology and Evolution, Vol. 18 No. 6, pp. 299-305.

Khaemba, W.M. (2000), Development and Application of Spatial and Temporal Statistical Methods for Unbiased Wildlife Sampling, Eldoret, Kenya.

Khaemba, W.M. and Stein, A. (2000), "Use of GIS for spatial and temporal analysis of Kenyan wildlife with generalised linear modelling", International Journal of Geographical Information Science, Vol. 14 No. 8, pp. 833-853.

Magurran, A.E. (2004), Measuring Biological Diversity, Blackwell Science, Oxford.

Martin, F., Cunliffe, R., Farcomeni, A., De Sanctis, M., D’Ammando, G. and Attore, F. (2016), "Classification and mapping of the woody vegetation of Gonarezhou national park, Zimbabwe", Koedoe, Vol. 58 No. 1, pp. 1-10.

Matthews, T.J. and Whittaker, R.J. (2014), "Fitting and comparing competing models of the species abundance distribution: assessment and prospect", Frontiers of Biogeography, Vol. 6 No. 2, pp. 66-82.

Ndaimani, H., Murwira, A., Masocha, M., Gara, T.W. and Zengeya, F.M. (2017), "Evaluating performance of aerial survey data in elephant habitat modelling", African Journal of Ecology, Vol. 55 No. 3, pp. 270-281.

Oindo, B.O. (2008), "Predicting mammal species richness from remotely sensed data at different spatial scales", The Open Remote Sensing Journal, Vol. 1 No. 1, pp. 7-16.

Oindo, B. and Skidmore, A.K. (2002), "Interannual variability of NDVI and species richness in Kenya", International Journal of Remote Sensing, Vol. 23 No. 2, pp. 285-298.

Oliveira, F.F. and Batalha, M.A. (2005), "Lognormal abundance distribution of woody species in a cerrado fragment (São Carlos, southeastern Brazil)”, Revista Brasileira de Botânica, Vol. 28 No. 1, pp. 39-45.

Omondi, P., Mayienda, R., Mshelbwala, J.H. and Massalatchi, M.S. (2006), "Total aerial count of elephants, buffaloes, roan antelope and other wildlife species in Yankari ecosystem, Nigeria report", European Union, Yankari.

Pettorelli, N., Bro-Jørgensen, J., Durant, S.M., Blackburn, T. and Carbone, C. (2009), "Energy availability and density estimates in African ungulates", The American Naturalist, Vol. 173 No. 5, pp. 698-704.

Pettorelli, N., Vik, J.O., Mysterud, A., Gaillard, J.M., Tucker, C.J. and Stenseth, N.C. (2005), "Using the satellite-derived NDVI to assess ecological responses to environmental change", Trends in Ecology and Evolution, Vol. 20 No. 9, pp. 503-510.

Preston, F.W. (1948), “The commonness, and rarity, of species”, Ecology, Vol. 29 No. 3, pp. 254-283. 
Redfern, J.V., Viljoen, P.C., Kruger, J.M. and Getz, W.M. (2002), "Biases in estimating population size from an aerial census: a case study in the Kruger national park, South Africa", South African Journal of Science, Vol. 98 No. 9, pp. 455-446.

Schlossberg, S., Chase, M.J. and Griffin, C.R. (2016), "Testing the accuracy of aerial surveys for large mammals: an experiment with African savanna Elephants (Loxodonta africana)", PLoS One, Vol. 11 No. 10, pp. 1-18.

Taylor, D., Ellis, J. and Cushman, H. (2018), "Indirect effects of the large mammalian herbivore on small mammal populations: context-dependent variation across habitat types, mammalian species and seasons", Ecology and Evolution, Vol. 8 No. 23, pp. 1-19.

Verberk, W.C.E.P. (2011), "Explaining general patterns in species abundance and distributions", Nature Education Knowledge, Vol. 3 No. 10, pp. 1-11.

Villarreal, M.L., Gass, L., Norman, L., Sankey, J.B., Wallace, C.S.A., Childs, J.L. and Petrakis, R. (2013), "Examining wildlife responses to phenology and wildfire", Conference Paper", AZ, pp. 503-505.

Walter, M.J. and Hone, J. (2003), "A comparison of 3 aerial survey techniques to estimate wild horse abundance in the Australian Alps", Wildlife Society Bulletin, Vol. 31 No. 4, pp. 1138-1149.

Winterbach, C.W., Whitesell, C. and Somers, M.J. (2015), "Wildlife abundance and diversity as indicators of tourism potential in Northern Botswana", PLoS One, Vol. 10 No. 8, pp. 1-22.

\section{Further reading}

Beck, J.L. and Suring, L.H. (2008), Wildlife Habitat-Relationships Models: Description and Evaluation of Existing Frameworks in Models for Planning Wildlife Conservation in Large Landscapes, Joshua, J., Millspaugh, F.R. and Thompson, III. (Eds), Elsevier Science, Chicago, pp. 251-286, available at: www.northern-ecologic.com/publications/Frameworks.pdf

Cunliffe, R., Muller, T. and Mapaura, A. (2012), Vegetation survey of Gonarezhou National Park, Zimbabwe Report, Frankfurt Zoological Society and Zimbabwe Parks and Wildlife Management Authority Harare, available at: https://gonarezhou.org/wp-content/uploads/2018/ 08/GNP-Vegetation-Report.pdf

Dunham, K.M. (2001), Aerial census of elephants and other large herbivores in Gonarezhou National Park and some bordering lands, Zimbabwe: 200 Report, Frankfurt Zoological Society and Zimbabwe Parks and Wildlife Management Authority, Harare, available at: http:// d2ouvy59p0dg6k.cloudfront.net/downloads/gonarezhou_report.pdf

Dunham, K.M. (2015), Aerial survey of elephants and other large herbivores in Gonarezhou National Park and Save Valley Conservancy (Zimbabwe): 2014 Report, Frankfurt Zoological Society and Zimbabwe Parks and Wildlife Management Authority, Harare.

Ndegwa Mundia, C. and Murayama, Y. (2009), "Analysis of land use/cover changes and animal population dynamics in a wildlife sanctuary in East Africa", Remote Sensing, Vol. 1 No. 4, pp. 952-970.

Williamson, M. and Gaston, K. (2005), "The lognormal distribution is not an appropriate null hypothesis for the species-abundance distribution”, Journal of Animal Ecology, Vol. 74 No. 3, pp. 409-422.

\section{Corresponding author}

Talent Murwendo can be contacted at: dmurwendo@gmail.com

For instructions on how to order reprints of this article, please visit our website:

www.emeraldgrouppublishing.com/licensing/reprints.htm

Or contact us for further details: permissions@emeraldinsight.com 